\title{
Estimating Rotational Iron Losses in an Induction Machine
}

\author{
Carlos A. Hernandez-Aramburo, Member, IEEE, Tim C. Green, Senior Member, IEEE, and \\ Alexander C. Smith, Senior Member, IEEE
}

\begin{abstract}
We present an assessment of the effect of rotational losses on an induction machine. The assessment provides an estimate of the iron losses in an induction machine by three methods, all of which rely on the output data of a two-dimensional finite-element method: 1) calculating iron losses as if they were produced by a purely alternating field; 2) calculating the iron losses by adding the losses produced by the orthogonal components of the flux density, as if the losses produced by these components were independent phenomena; 3) applying a correction factor based on experimental data to improve the rotational loss calculation. The correction factor is a function of the peak flux density value and the ratio of the major to the minor axis of the flux density loci. The third method represents the main contribution of this paper to the field and is explained in detail. Finally, a discussion of the results addresses two aspects: the location where rotational fields occur, and their impact on the total loss calculation.
\end{abstract}

Index Terms-Induction machines, induction motors, iron losses, rotational losses.

\section{INTRODUCTION}

I RON LOSS calculation should, ideally, be an integral part of the model of the iron magnetization process. However, this idea is still too ambitious for the state of the art in magnetization modeling [1]. Preisach models, which are aimed at improving the representation of magnetic phenomena are rapidly being put into practice [2], [3], but they are still at an early stage. A more widely used approach to represent iron losses in a lamination is to use some form of averaging over time and volume [4].

In the field of induction machines, these average-based approaches have been used in conjunction with finite-element (FE) techniques to segregate iron losses, according to their nature, into hysteresis, classic eddy-current, and anomalous losses [5], [6]. Somewhat overlooked is the loss assessment under rotating flux conditions. This phenomenon is of special interest for the accurate calculation of iron loss in induction machines because it has been widely reported that the losses produced by a rotational field (in a nongrain-oriented material) are considerably larger than those produced by an alternating field of the same peak magnitude [7], [8]. Thus, in regions of the motor where

Manuscript received June 4, 2003; revised August 28, 2003.

C. A. Hernandez-Aramburo and T. C. Green are with Imperial College London, London SW7 2BT, U.K. (e-mail: c.hernandez@imperial.ac.uk; t.green@imperial.ac.uk).

A. C. Smith is with the University of Manchester Institute of Science and Technology, Manchester M60 1QD, U.K. (e-mail: sandy.smith@umist.ac.uk).

Digital Object Identifier 10.1109/TMAG.2003.819451 the field is essentially rotational, a miscalculation of the losses may occur.

This work provides an estimate of the iron losses in an induction machine by three methods. In all cases, a twodimensional (2-D) FE simulation technique is used to provide the underlying magnetic field data. The intended contribution of this paper to the field of iron losses in induction machines is in the third method, where an experimental factor is employed to improve the accuracy in the calculation of the iron losses under rotating field conditions.

\section{SYSTEM REPRESENTATION}

The simulation strategy used in this paper is based on work by Williamson et al. [9]. In broad terms, the induction motor simulation is governed by

$$
\begin{aligned}
\frac{\mathrm{d}}{\mathrm{d} \mathbf{t}}[\mathbf{\Psi}] & =\left[\mathbf{V}_{\mathrm{ph}}\right]-[\mathbf{R}][\mathbf{I}] \\
{[\mathbf{I}] } & =[\mathbf{L}]^{-1}[\mathbf{\Psi}] .
\end{aligned}
$$

The stator variables are in the $A B C$ reference frame, while a $d q$ model is employed to represent the rotor; $\mathbf{R}$ is the resistance matrix; $\mathbf{V}$, the phase voltages; $\mathbf{I}$, phase currents; $\boldsymbol{\Psi}$, the flux linkages, and $\mathbf{L}$ is the inductance matrix. The motor nonlinearities are accounted for by continuously recomputing $\mathbf{L}$ by FE analysis.

The machine under study is a delta-connected $2.1-\mathrm{kW} 50-\mathrm{Hz}$ 1425-r/min 4-pole cage induction motor. This machine has two unusual features: the supply line voltage is $240 \mathrm{~V}$ and the rotor is unskewed. A straight rotor was chosen to keep the simulation time to a minimum; otherwise, a multislice simulation technique would have been more suitable [10] at the expense of a longer simulation time.

Commissioning the FE-based model and verification against experimental results have been carried out in previous research [11], [12]. In these works, some modifications were made to the original simulation model to facilitate the use of an inverter-based power supply and estimate the power losses with a pulsewidth modulation-based excitation. The current work is solely aimed at estimating the rotational losses under sinusoidal excitation.

The first part of the loss analysis is performed for the machine operating at full-load conditions (slip of 0.05). 


\section{Method A. Purely Alternating Losses}

Although there are several variants of the calculation of hysteresis, classic eddy-current, and anomalous losses, one widely accepted set of expressions is given by [6]

$$
\begin{aligned}
P_{\text {iron }} & =P_{\text {hys }}+P_{\text {eddy }}+P_{\text {anom }} \\
P_{\text {hys }} & =k_{1 \text { hys }} f B_{p k}^{k_{2 \text { hys }}}\left(1+\frac{k_{3 \text { hys }}}{B_{p k}} \sum_{i}^{N} \Delta B_{i}\right) \\
P_{\text {eddy }} & =\frac{\sigma \delta^{2}}{12} \frac{1}{T} \int_{T}\left(\frac{d B}{d t}\right)^{2} d t \\
P_{\text {anom }} & =\frac{k_{\text {anom }}}{T} \int_{T}\left|\frac{d B}{d t}\right|^{\frac{3}{2}} d t
\end{aligned}
$$

where

$P_{\text {iron }} \quad$ iron power loss density $\left[\mathrm{W} / \mathrm{m}^{3}\right]$;

$P_{\text {hys }} \quad$ hysteresis loss density $\left[\mathrm{W} / \mathrm{m}^{3}\right]$;

$P_{\text {eddy }} \quad$ classic eddy current loss density $\left[\mathrm{W} / \mathrm{m}^{3}\right]$;

$P_{\text {anom }}$ anomalous loss density $\left[\mathrm{W} / \mathrm{m}^{3}\right]$;

$\mathbf{B}, B_{p k}$ flux density, peak flux density [T];

$\Delta B_{i} \quad$ amplitude of the $i$ th minor loop [T];

$N \quad$ number of minor loops;

$T$ period of the waveform [s];

$k_{1 \text { hys }} \quad$ hysteresis loss linear constant;

$k_{2 \text { hys }} \quad$ hysteresis loss exponential constant;

$k_{3 \text { hys }}$ hysteresis loss minor loops constant;

$k_{\text {anom }}$ anomalous loss constant;

$\sigma \quad$ lamination conductivity [S/m];

$\delta \quad$ lamination thickness [m].

The values of the constants used cannot be published here because they are restricted by commercial confidentiality.

Equations (3)-(6) account for the losses in a lamination under a purely alternating field only. These equations, by themselves, do not tackle the problem of calculating the losses produced by a field whose locus is changing direction within the plane of the lamination (i.e., rotating). To illustrate the difference between these two types of variations of field, their flux density loci are depicted in Fig.1 (a) (alternating) and (b) (rotating).

A first approach to estimating the iron losses in a lamination may be to apply (3)-(6) to the component of the flux density along the major axis only. The component acting along the minor axis is ignored. The rotational loss calculation, therefore, becomes a problem using purely alternating field conditions. This method is not widely used because it entirely neglects the contribution of the minor axis component; but, for the sake of comparison, it is presented here. This approach indicates how poor the estimate of the rotational losses can be.

Equations (3)-(6) were applied as a post-processing stage to the $\mathbf{B}$ waveforms obtained by the FE simulation using the component of $\mathbf{B}$ along the major axis. This resulted in a calculated iron loss of $49 \mathrm{~W}$ ( $32 \mathrm{~W}$ in the stator and $17 \mathrm{~W}$ in the rotor).

\section{Method B. LOSSES BY INDEPENDENT ORTHOGONAL COMPONENTS}

A better approximation to estimate the iron losses in an electrical machine is to take into account both spatial components

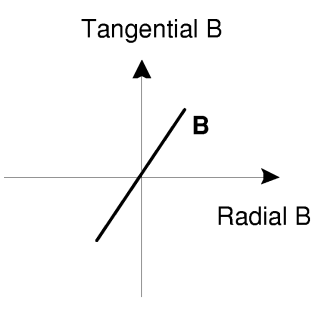

(a)

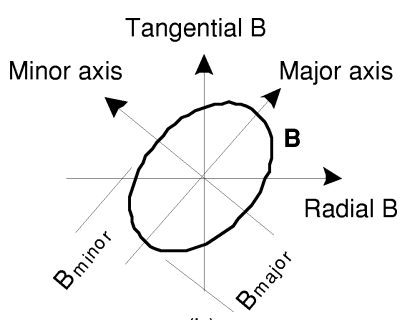

(b)
Fig. 1. B-locus shapes. (a) Purely alternating. (b) Rotational.

of the flux density vector. A common approach is to consider that the losses produced by the major and minor axis components are independent from each other. Therefore, the rotational losses may be estimated by summing up the losses produced by the two components [5], [10], [11], [13]. However, as has been acknowledged in all these works, this approach may not be entirely accurate.

Applying (3)-(6) to the orthogonal components of the flux density vector obtained by the FE analysis results in an estimation of the losses of $57 \mathrm{~W}(35 \mathrm{~W}$ in the stator and $22 \mathrm{~W}$ in the rotor).

\section{Method C. Losses by Applying a CORReCtion FACTOR}

A further improvement to estimating the rotational losses may be achieved by employing a correction factor to account for the peak induction level and a measure of the rotating nature of the field. Such a measure may be defined by taking the ratio of the minor to the major axis of the flux density locus $\left(\left|B_{\text {minor }}\right|\right) /\left(\left|B_{\text {major }}\right|\right)$ (see Fig. 1). This ratio (confined between 0 and 1) defines the aspect ratio of a particular B-locus. A value of zero corresponds to a pure alternating field; and the closer the ratio is to 1 , the more the $\mathbf{B}$-locus resembles a circle.

A correction factor that accounts for the peak induction and the aspect ratio of a rotating field has been proposed by Kochmann [14]. In this reference, a loss factor is introduced as a means of relating the rotational losses in a simple-geometry lamination with the sum of the losses produced by the orthogonal components of $\mathbf{B}$

$$
\gamma\left(\lambda, B_{p k}\right) \triangleq \frac{P_{\text {rot }}\left(\lambda, B_{p k}\right)}{P_{0^{\circ}}\left(B_{p k}\right)+P_{90^{\circ}}\left(\lambda B_{p k}\right)}
$$

where

$P_{\text {rot }} \quad$ losses produced by an elliptical field [W];

$\lambda$ aspect ratio. Ratio between the minor and major axis of a particular B-locus: $\lambda \triangleq\left(\left|B_{\text {minor }}\right|\right) /\left(\left|B_{\text {major }}\right|\right)$ [dimensionless];

$P_{0^{\circ}}\left(B_{p k}\right) \quad$ alternating losses produced by $\mathbf{B}$ parallel to the rolling direction $[\mathrm{W}]$;

$P_{90^{\circ}}\left(\lambda B_{p k}\right)$ alternating losses produced by $\mathbf{B}$ perpendicular to the rolling direction $[\mathrm{W}]$;

$B_{\text {major }} \quad$ major axis of the flux density locus [T];

$B_{\text {minor }} \quad$ minor axis of the flux density locus [T];

$B_{p k} \quad$ peak flux density along the major axis [T].

In [14], two important functions related to the loss factor were illustrated graphically. One is the behavior of the loss factor against the aspect ratio, which is plotted for several flux density peak magnitudes: $0.1,0.5,1.0$, and $1.5 \mathrm{~T}$. The second function 


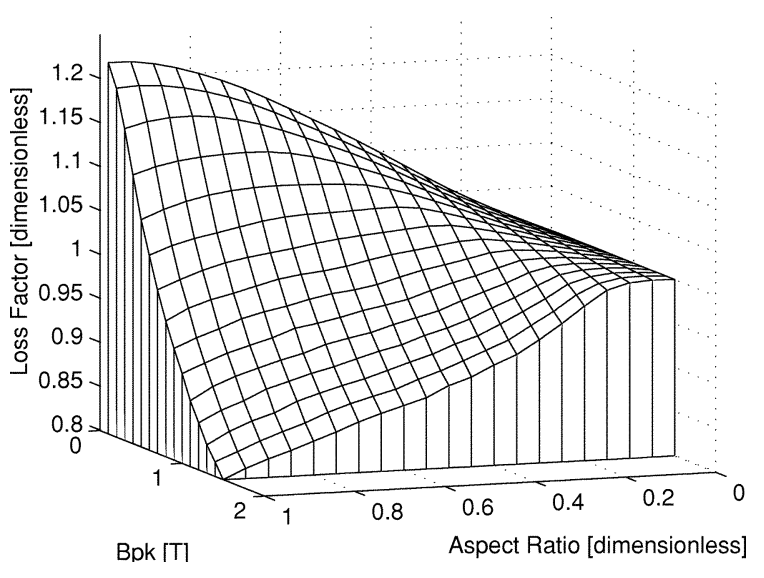

Fig. 2. Loss factor as a function of the peak flux density and the aspect ratio using data from Kochmann's paper.

is a loss factor ratio $(\xi)$, defined by (8), which is plotted against the product $\lambda B_{p k}$. The plot for this second function appears to be largely independent of the peak flux density

$$
\xi \triangleq \frac{\gamma\left(\lambda, B_{p k}\right)}{\left.\gamma\left(\lambda, B_{p k}\right)\right|_{B_{p k=0.1 T}}} .
$$

With these two functions, the loss factor for any $\lambda$ and $B_{p k}$ (within the limits of the experimental data presented in that paper) may be calculated as follows:

$$
\gamma\left(\lambda, B_{p k}\right)=\left.\xi \gamma\left(\lambda, B_{p k}\right)\right|_{B_{p k=0.1 T}} .
$$

Both functions $\xi$ and $\gamma(\lambda, 0.1)$ in (9) are to be read from the plots presented in [14]. Fig. 2 is a reconstruction of $\gamma$ in a threedimensional mesh, plotted against the peak flux density and the flux density aspect ratio. A "curtain" has been set at the edges of the mesh to make the shape of $\gamma$ easier to visualize in the 3-D space.

Fig. 2 has several characteristics that are particularly relevant to the study of induction machines, where it is not uncommon to find peak flux densities larger than $1 \mathrm{~T}$.

1) At an induction level of $1.0 \mathrm{~T}$ and $\lambda>0.4, \gamma$ decreases with $\lambda$ and is smaller than 1.0.

2) At an induction level of $1.5 \mathrm{~T}, \gamma$ decreases with $\lambda$ and is smaller than 1.0 for any value of $\lambda$.

3) At an induction level of $1.5 \mathrm{~T}$, the minimum value for $\gamma$ was found to be close to 0.8 .

Finally, by substituting (9) into (7) and solving for $P_{\text {rot }}$, the iron losses in a lamination of simple geometry produced under rotating flux conditions may be calculated with

$$
P_{\mathrm{rot}}=\left[P_{0^{\circ}}\left(B_{p k}\right)+P_{90^{\circ}}\left(\lambda B_{p k}\right)\right] \xi \gamma(\lambda, 0.1) .
$$

Another result that is presented in [14] is the loss ratio plotted against several flux density peak values for a circular field $(\lambda=$ $1)$. This experiment has not an immediate application to the present work, but it is interesting to note that a similar result may be indirectly obtained with the experimental data presented by Findlay et al. [15]. This agreement between two different researchers adds a degree of confidence to the experimental measurements by Kochmann, on whose correction factor the present work is based.

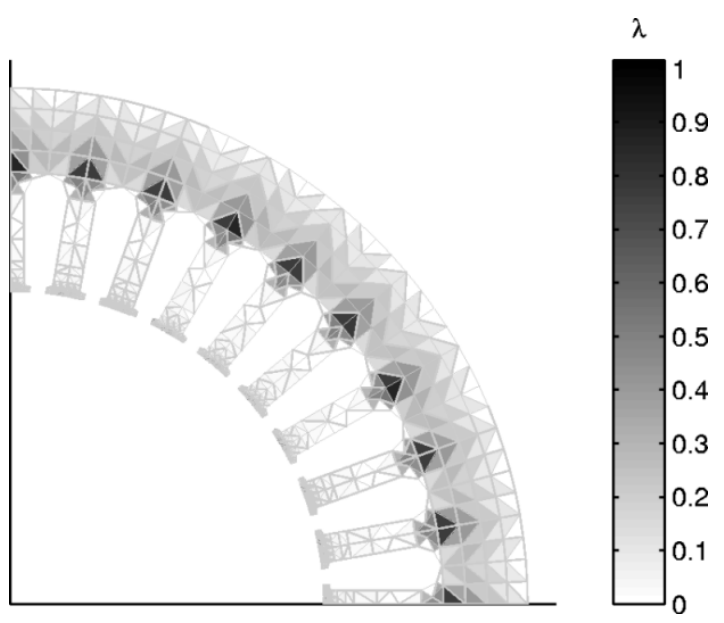

Fig. 3. Aspect ratios in the stator.

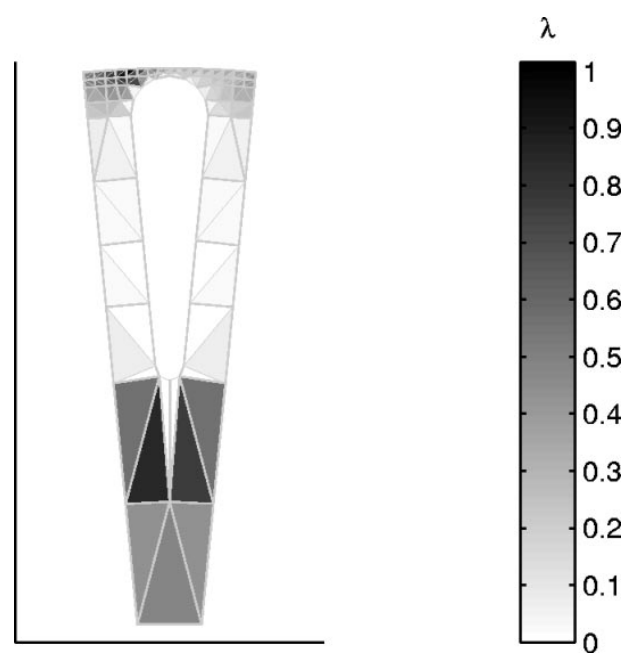

Fig. 4. Aspect ratios in the rotor.

If (10) is to be used to calculate the iron loss for each finite element in the motor iron mesh, the ratio of the minor to the major axis of the $\mathbf{B}$-locus, the peak value of the flux density, and the loss factor must be found first. These results are shown in the next sections.

\section{A. Minor to Major Axis Ratio}

Fig. 3 shows (on a gray scale) the ratio between the minor and major axis scale for the stator. The region at the base of the stator teeth shows the largest value of $\lambda$ with the back iron being next in importance. This is to be expected, however, because the radial tooth flux which emerges into the back-iron has to rotate into the circumferential direction. The circumferentially rotating field in the machine therefore produces a local rotational field at the base of the stator teeth as the pole zeroes pass by. The field distribution becomes increasingly more elliptical as one moves out radially through the core back, becoming almost purely alternating at the outer core boundary. The flux density along the tooth-bodies is predominantly alternating as expected. The only tangential components found in this region are due to the leakage flux around the phase coils.

Fig. 4 shows the values for $\lambda$ calculated for the rotor. The solution of the finite-element method is carried out for quarter 


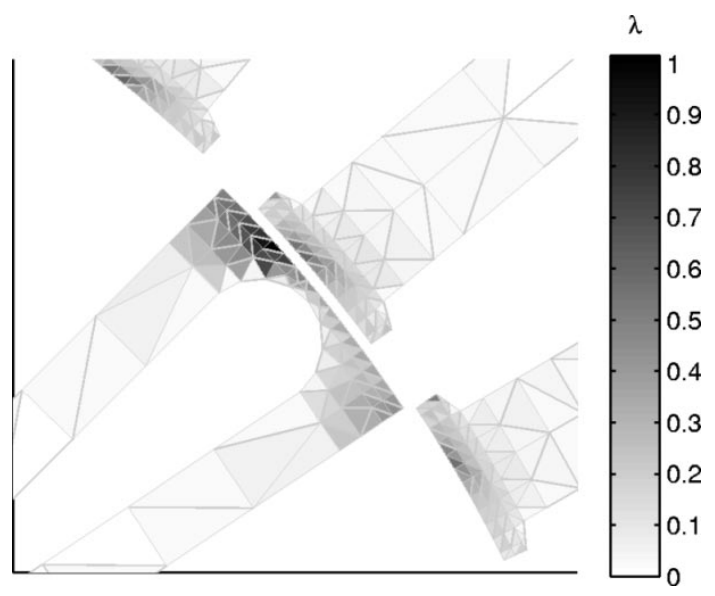

Fig. 5. Aspect ratios near the air gap.

of the machine, but the results for the rotor are presented here only in a single slot pitch. As may be observed from Fig. 4, the region close to the rotor surface presents the largest ratio between the minor and major axes. The field along the rotor teeth are essentially alternating, but the rotor inner core shows a relatively high $\lambda$ at the base of the rotor teeth for the same reasons as the stator teeth.

A close-up of the air-gap region is shown in Fig. 5. In the stator tooth tips, a slightly higher aspect ratio was obtained toward the middle of the tips. In the rotor, a higher $\lambda$ is observed in the middle of the tooth-tips (at the sides of the rotor slot shown in this figure) than in the rotor bridge. The stator and rotor tooth face regions usually form the path for the high pole number slotting field harmonics. These field components have pole numbers closely related to the stator and rotor slot numbers and tend to "zig-zag" along the stator/rotor air-gap interface. The tooth faces therefore commonly include areas of rotational field excitation.

Fig. 6 shows the value of $\lambda$ of each finite element in the stator and rotor against the radial distance. In this figure, the peak at the approximate normalized radial distance 0.6 corresponds to the stator and rotor air-gap surfaces. It is possible to build this plot because of the symmetry of the aspect ratio in the stator and rotor (noticeable in Figs. 3 and 4, respectively). Fig. 6 has the advantage that the values for $\lambda$ are easier to identify than in the gray-scale maps.

\section{B. Peak Flux Density}

The peak flux density along the major axis is plotted in Fig. 7. In this plot, there are several regions that can be clearly identified. On the rotor side, the peak flux density becomes higher in the direction from the shaft to the air gap: passing through the rotor back-iron, the rotor teeth, the rotor tooth tips, and finally the rotor bridge region. A particularly large $B_{p k}$ may be observed in the rotor bridge. This is expected because this region is heavily driven into saturation during a rotor fundamental cycle. On the stator side, there are also some regions that can be clearly identified according to the flux density peak values: the tooth tips, the tooth bodies, the tooth roots, and finally the back-iron.

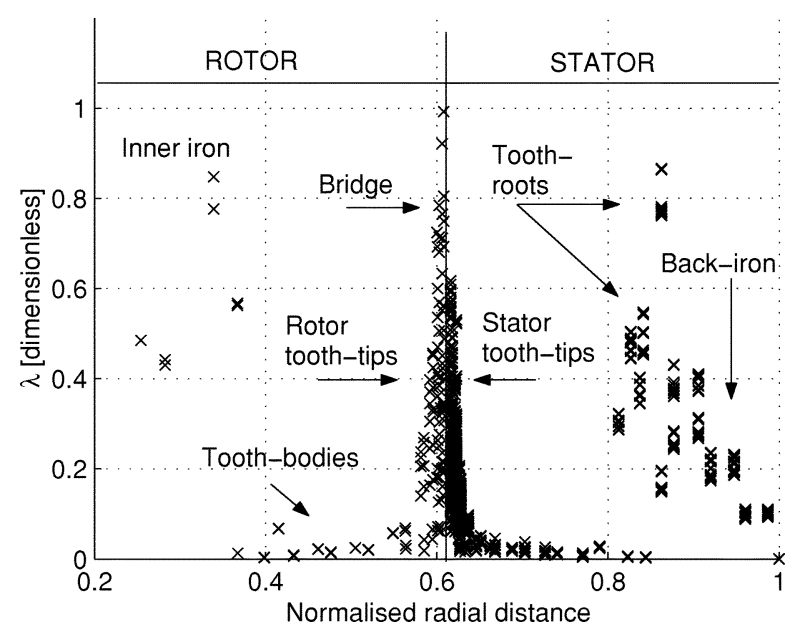

Fig. 6. Minor to major axis ratio against radial distance.

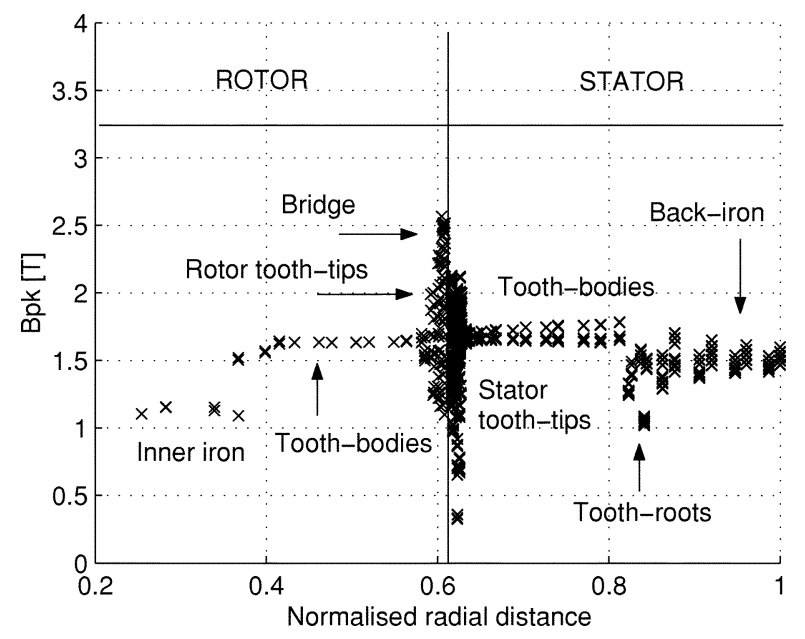

Fig. 7. $B_{p k}$ against radial distance.

\section{Loss Factor}

With the values of $\lambda$ and $B_{p k}$ calculated in the previous sections, the loss factor may be obtained from (9). Fig. 8 shows the loss factor plotted against the radial distance. In this figure, it can be observed that the regions where the field is mainly alternating (rotor and stator tooth-bodies) the correction factor is close to one. For these largely alternating fields, the correction factor has little effect in the estimation of rotational losses when they are calculated by adding the losses produced by the orthogonal components of the field. A slightly larger correction is applied in the stator and rotor back-iron, where $\gamma$ was calculated between 0.9 and 1.0. This indicates that summing the losses produced by the orthogonal components of the flux density overestimates the losses by $10 \%$ in these regions. For the stator tooth-roots and the iron immediately underneath the rotor bars (see large dark areas in Fig. 4), the loss factor was close to 0.85 and for the rotor bridge to values just above 0.80 . In these three regions, the correction factor has a more significant impact because either $\mathbf{B}$ has a relatively large aspect ratio (in the case of the tooth-roots and the areas underneath the bars) or the peak flux density is particularly large (rotor bridge). 
The inclusion of the loss factor in the rotational loss calculation brings the calculated loss down to $54 \mathrm{~W}$ ( $34 \mathrm{~W}$ in the stator, $20 \mathrm{~W}$ in the rotor).

It is worth pointing out that Figs. 6-8 may be slightly misleading. Every mark in these figures represents the value obtained for $\lambda, B_{p k}$, and $\gamma$ (respectively) for a particular finite element in the mesh, and this value may not be the most representative of the region where the element is located. The particular size and location of an element within a region, and the mesh structure itself are three aspects that make some elements more or less representative of a region than others. The second difficulty is that, due to the scales required by the plots, there may be several marks overlapping such that it looks as if there are fewer elements at a particular radial distance. Nevertheless, Figs. 6-8 do provide a good insight to the values of $\lambda, B_{p k}$, and $\gamma$ found in the simulations for the various regions of the motor laminations.

Fig. 9 shows the impact of the loss factor on the sum of the losses calculated independently for the two orthogonal components of $\mathbf{B}$. This figure shows the percentage of the total iron losses (stator plus rotor losses without any correction applied yet) that are associated with particular loss factor $\gamma$. The bars for the rotor lie above those for the stator. This figure indicates that $38 \%$ of the motor losses have a loss factor $\gamma=1 \pm 0.01$ applied to them $( \pm 0.01$ corresponds to the width of each bar in Fig. 9). This $38 \%$ is made of $32 \%$ on the stator and $6 \%$ on the rotor side. In general, the bars in Fig. 9 indicate that the losses on the stator side are largely unaffected because the stator losses are mainly associated with loss factors between 0.95 and 1.0. The rotor loss bars indicate that a significant portion of the rotor losses are located in elements where the correction factor was calculated between 0.8 and 0.95 . It was expected that the rotor losses would have a significant correction factor applied to them because they are dominated by the loss in the elements close to the surface [16], where high peak flux densities and high aspect ratios are normally found.

\section{DisCUSSION OF RESULTS}

Table I presents the summary of the results obtained in the preceding sections: considering the losses as purely alternating (method A), calculating rotational losses by adding the losses produced by the orthogonal components of the flux density ( $\operatorname{method} \mathbf{B})$, and applying a empirical correction factor to the orthogonal sum (method $\mathbf{C})$.

The loss difference between methods A and B ( $8 \mathrm{~W})$ corresponds to the losses produced by the nondominant orthogonal component of the flux density. In percentage terms, this difference accounts for $(8) /(49) \times 100 \approx 18.4 \%$. In terms of location, this loss difference is produced in the elements with a relatively large $\lambda$ (see Figs. 3-6).

In Table I, the results obtained by method $C$ are considered more accurate than the other two and therefore they were taken as the reference case. Method A underpredicts the total losses (by $9.3 \%$ ) because it neglects the losses produced by one of the orthogonal components of the flux density. On the other hand, method B overpredicts the losses (by 5.6\%) because it overlooks the fact that, at a typical magnetic specific load of an in-

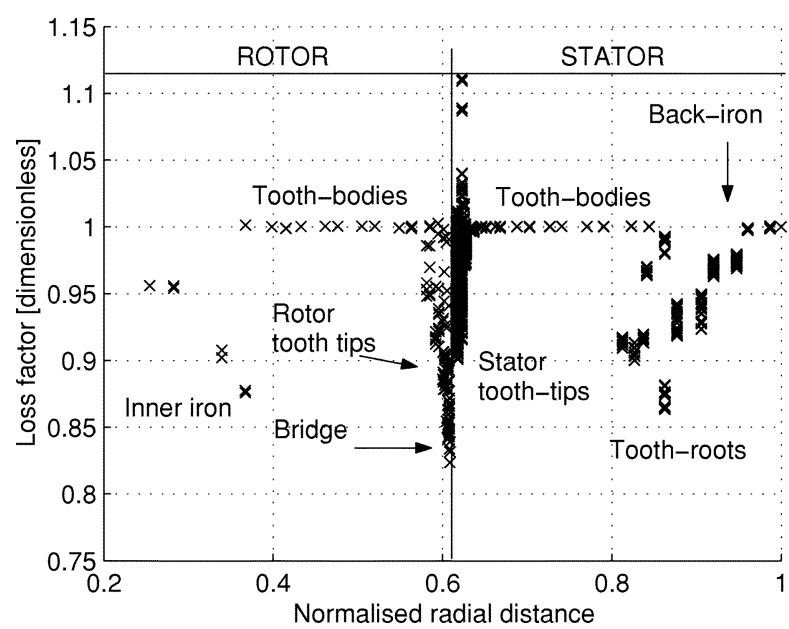

Fig. 8. Loss factor against radial distance.

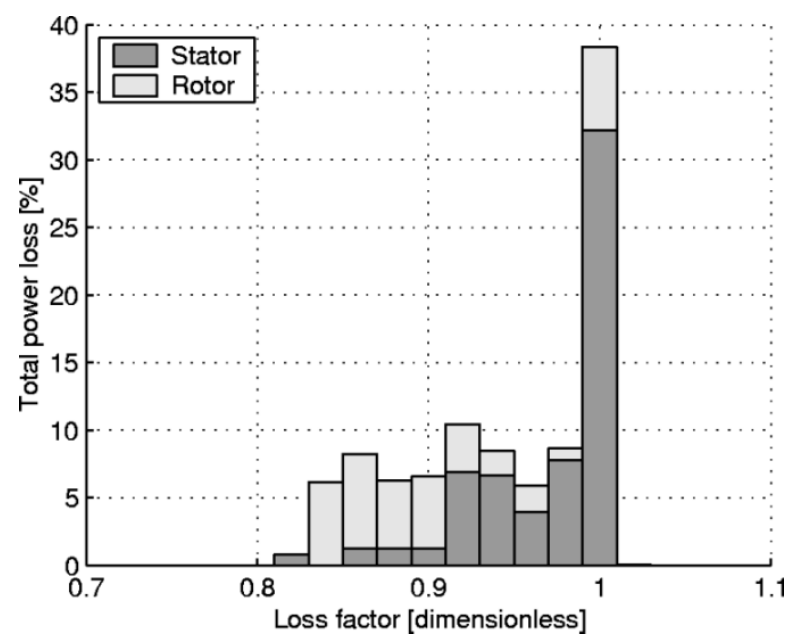

Fig. 9. Percentage of the total iron power loss versus loss factor.

TABLE I IRON LOSS CALCULATION UNDER FULL-LOAD CONDITIONS

\begin{tabular}{c|cc|cc|cc}
\hline Method & \multicolumn{2}{|c}{ Stator } & \multicolumn{2}{c}{ Rotor } & \multicolumn{2}{c}{ Total } \\
& [W] & Diff. & [W] & Diff. & [W] & Diff. \\
\hline $\mathbf{A}$ & 32 & $-5.9 \%$ & 17 & $-15 \%$ & 49 & $-9.3 \%$ \\
$\mathbf{B}$ & 35 & $+2.9 \%$ & 22 & $+10 \%$ & 57 & $+5.6 \%$ \\
$\mathbf{C}$ & 34 & - & 20 & - & 54 & - \\
\hline
\end{tabular}

TABLE II

IRON LOSS CALCULATION UNDER LIGHT-LOAD CONDITIONS

\begin{tabular}{c|cc|cc|cc}
\hline Method & \multicolumn{2}{|c}{ Stator } & \multicolumn{2}{c}{ Rotor } & \multicolumn{2}{c}{ Total } \\
& {$[\mathrm{W}]$} & Diff. & [W] & Diff. & [W] & Diff. \\
\hline $\mathbf{A}$ & 30 & $-3.2 \%$ & 15 & $-6.25 \%$ & 45 & $-4.3 \%$ \\
$\mathbf{B}$ & 32 & $+3.2 \%$ & 19 & $+18.8 \%$ & 51 & $+6.4 \%$ \\
$\mathbf{C}$ & 31 & - & 16 & - & 47 & - \\
\hline
\end{tabular}

duction machine, saturation (associated with a high peak flux density) plays an important role in the loss mechanisms. The largest deviation between methods $\mathrm{B}$ and $\mathrm{C}$ is observed in the rotor $(+10.0 \%)$. This deviation occurs because the losses in the rotor are dominated by the losses in the tooth-tips and bridge, and in these regions the loss calculation by method B is significantly corrected by the loss factor, as discussed in the preceding section. 
A similar analysis to the one presented so far for the full-load operating condition was performed for a light-load condition (slip of 0.01), and the results are summarized in Table II.

For the light-load condition, method A undercalculated the losses by $4.3 \%$ and method B overestimated the losses by $6.7 \%$ (again, taking method $\mathrm{C}$ as reference).

Method B provides a less accurate loss estimate for light-load conditions than for the full-load case. This occurs because, in general, the main flux path in the machine has a larger flux density at light-load than at full-load conditions. Under these circumstances the value of $\gamma$ will be, on average, smaller for the light-load case. The correction that $\gamma$ imposes over the sum of orthogonal components was estimated to be as important as $18.8 \%$ for the rotor.

The test motor used in this investigation had a low power rating $(2.1 \mathrm{~kW})$ and the iron losses in such a machines are normally only a small proportion of the total losses, typically $10 \%$. The remaining losses would be associated with the copper losses in the stator and rotor windings. As a consequence, the rotational iron losses have little impact on the total loss of the motor. In machines of increasing power ratings, the proportion of the total losses associated with iron losses also increases to around $35 \%$ in machines with ratings in excess of $100 \mathrm{~kW}$ or so. The impact of rotational iron losses would also become more apparent in the total losses of these motors.

\section{ASPECTS FOR FURTHER CONSIDERATION}

The present work has indirectly extrapolated the data in [14]. The product $\lambda B_{p k}$ required to obtain $\xi$ in (9) for any finite element does fit within the data plots presented by Kochmann; however, these plots were obtained for a peak flux density up to $1.5 \mathrm{~T}$ and the peak flux densities for some elements exceeds this value. This suggests that further experimentation should be carried out to extend the range presented in [14].

The tests in [14] correspond to an elliptical flux density loci and some finite elements have a B-locus that is far from being elliptical. Fig.10(a)-(d) show four loci at certain locations in the motor laminations. The loci in the back-iron and in the inner iron resemble an ellipse; however, approximating the loci in the stator tooth-tips and rotor bridge to an ellipse may compromise accuracy. In the present work, the value for $\left|B_{\text {minor }}\right|$ was defined as the maximum value that the $\mathbf{B}$-loci takes along the minor axis (as opposed to taking the value of $\mathbf{B}$ were the component along the major axis is zero).

The major axis of the flux density loci calculated for every element of the mesh is not generally in alignment with the rolling direction of the laminations, as required by (7). Normal methods of motor construction usually ensure there is no preferred magnetic direction in the pack of laminations. This means that the losses parallel and perpendicular to the rolling direction were assumed to be identical and, hence, no correction for any anisotropy in the lamination material was taken into account. However, the impact of material anisotropy correction on the loss calculation has been found to be small [8].

An aside in [17] (which has been widely quoted by other authors) suggests that the rotational losses can account for $50 \%$

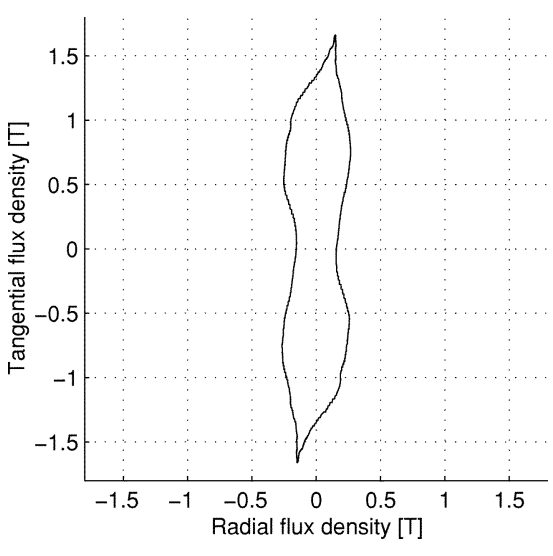

(a)

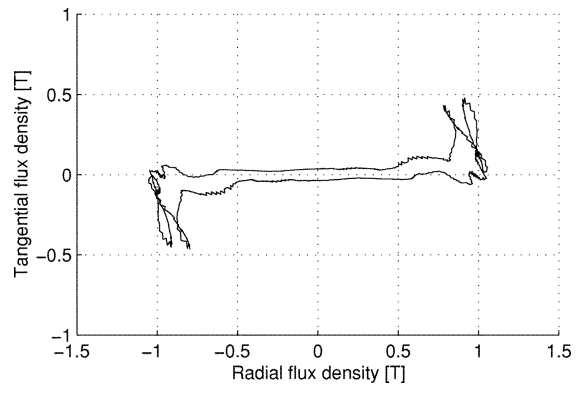

(b)

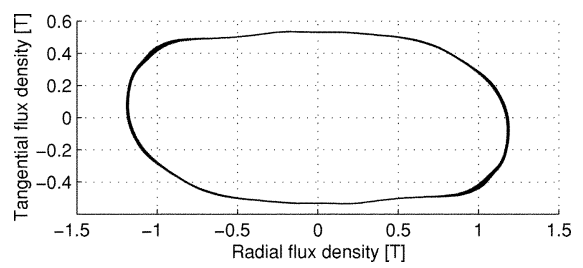

(c)

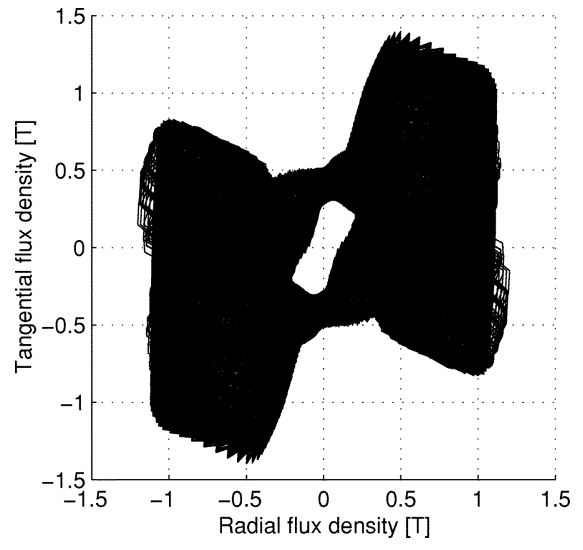

(d)

Fig. 10. B-loci for: (a) back-iron, (b) stator tooth-tip, (c) rotor inner core, and (d) rotor bridge.

of the iron losses in the stator. The results here show a much smaller variation (of approximately $6 \%$ at full-load conditions and $3 \%$ at light-load conditions) between the losses calculated by a purely alternating field and the rotational losses determined by the loss factor put forward by Kochmann. In this study, no evidence was found to support the comment in [17]. It has been widely reported [15] that, at certain induction levels, the rotational losses of a purely circular field may be larger than the 
alternating losses produced by any of the orthogonal components of the flux density acting alone; however, a circular field (or more generally, a field with a large aspect ratio) is not a condition typical of the whole stator, but a very localized phenomenon, as shown in this paper.

\section{CONCLUSION}

The iron losses in an induction machine have been estimated by three methods based on an FE simulation. Although similar numerical results were obtained for the machine under study by the three methods, there are important differences to consider.

Calculating the losses by assuming a purely alternating field may be acceptable for some applications; however, the rotational losses are entirely neglected. As a consequence of this, the losses are underestimated. An even more important issue is the fact that an error bound cannot be easily determined.

Calculating the motor iron losses by adding the losses produced independently by the major and minor axis components of the flux density does take into account the losses under rotating field conditions, but it overlooks the effects that a particular component of $\mathbf{B}$ may have in the loss mechanisms of its orthogonal component. This method performed better for full-load conditions than for the light-load case. Specifically, the largest deviation was obtained for the rotor, where saturation significantly affects the areas that dominate the total rotor loss. The major advantage of method B over method A is that it is possible to bound the error in the loss calculation. The error tolerance is given by the loss factor $\gamma$. In broad terms, the error was estimated to within $-10 \%$ for most of the area of the machine, and within $-20 \%$ in very specific areas of the stator and across the rotor surface. Whenever possible, a correction factor should be applied to improve the accuracy of the calculation of iron losses under rotating field conditions.

\section{ACKNOWLEDGMENT}

The first author thanks Consejo Nacional de Ciencia y Tecnologia-Mexico for funding his Ph.D. program at Imperial College London under scholarship number 115297.

\section{REFERENCES}

[1] G. Bertotti, Hysteresis in Magnetism for Physicists, Material Scientists and Engineers, 1st ed. New York: Academic, 1998.

[2] J. J. Gyselinck, L. R. Dupre, L. Vandevelde, and J. A. A. Melkebeek, "Calculation of no-load induction core losses using the rate-dependen Preisach model," IEEE Trans. Magn., vol. 34, pp. 3876-3881, Nov. 1998.

[3] J. Saitz, "Computation of the core loss in an induction motor using the vector Preisach hysteresis model incorporated in finite element analysis," IEEE Trans. Magn., vol. 36, pp. 769-773, July 2000.

[4] P. Beckley, "Modern steels for transformers and machines," IEE Power Eng. J., vol. XIII, pp. 190-200, Aug. 1999.

[5] M. A. Mueller, S. Williamson, T. J. Flack, K. Atallah, B. Baholo, D. Howe, and P. H. Mellor, "Calculation of iron losses from time-stepped finite-element models of cage induction machines," in Proc. Int. Conf. Electrical Machines and Drives, vol. 1, Sept. 1995, pp. 88-92.

[6] K. Atallah, Z. Q. Zhu, and D. Howe, "An improved method for predicting iron losses in brushless permanent magnet DC drives," IEEE Trans. Magn., vol. 28, pp. 2997-2999, Sept. 1992.
[7] M. Enokizono, T. Suzuki, J. Sievert, and J. Xu, "Rotational power loss of silicon steel sheet," IEEE Trans. Magn., vol. 26, pp. 2562-2564, Sept. 1990.

[8] N. Stranges and R. D. Findlay, "Measurement of rotational iron losses in electrical sheet," IEEE Trans. Magn., vol. 36, pp. 3457-3459, Sept. 2000.

[9] S. Williamson, L. H. Lim, and M. J. Robinson, "Finite element models for cage induction motor analysis," IEEE Trans. Ind. Applicat., vol. 26, pp. 1007-1017, Nov./Dec. 1990

[10] C. I. McClay and S. Williamson, "Influence of rotor skew on cage motor losses," IEE Proc. Electr. Power Applicat., vol. 145, pp. 414-422, Sept. 1998.

[11] C. A. Hernandez-Aramburo, T. C. Green, and A. C. Smith, "Assessment of power losses of an inverter-driven induction machine with its experimental validation," IEEE Trans. Ind. Applicat., vol. 39, pp. 994-1004, July-Aug. 2003.

[12] T. C. Green, A. C. Hernandez-Aramburo, and A. C. Smith, "Losses in grid and inverter supplied induction machine drives," Proc. Inst. Elect. Eng.-Electric Power Applications, to be published.

[13] A. C. Smith and G. Phipson, "Iron losses in cage induction motors," in Proc. Int. Conf. Electrical Machines and Drives, Sept. 1991, pp. 255-259.

[14] T. Kochmann, "Relationship between rotational and alternating losses in electrical steel sheets," J. Magn. Magn. Mater, vol. 160, pp. 145-146, July 1996.

[15] R. Findlay, N. Stranges, and D. K. MacKay, "Losses due to rotational flux in three phase induction motors," IEEE Trans. Energy Conversion, vol. 9, pp. 543-549, Sept. 1994.

[16] C. A. Hernandez-Aramburo, T. C. Green, and C. I. McClay, "Integrated simulation of an inverter driven induction motor," in Proc. Int. Conf. Power Electronics and Variable Speed Drives, 2000, pp. 560-565.

[17] A. J. Moses, "Electrical steels: past, present and future developments," Proc. Inst. Elect. Eng., vol. 137, pp. 233-245, Sept. 1990.

Carlos A. Hernandez-Aramburo (S'99-M'03) received the B.Sc. and M.Sc degrees from the Universidad de las Americas, Puebla, Mexico, in 1994 and 1998, respectively, and the Ph.D. degree from Imperial College, London, U.K., in 2003 .

$\mathrm{He}$ is currently a Research Associate in the Control and Power Research Group at Imperial College. His professional interests include electrical machines and drives, active power filters, and distributed generation.

Tim C. Green (M'89-SM'02) received the B.Sc.(Eng.) degree (first class honors) from Imperial College, London, U.K., in 1986 and the Ph.D. degree from Heriot-Watt University, Edinburgh, U.K., in 1990, both in electrical engineering.

He was a Lecturer at Heriot Watt University until 1994, and is now a Reader at Imperial College and member of the Control and Power Research Group. His research interest is in using power electronics and control to enhance power quality and power delivery. This covers FACTS, active power filters, distributed generation, uninterruptible supplies and energy efficient drive systems.

Dr. Green is a Chartered Engineer in the U.K. and MIEE.

Alexander C. Smith (M'89-SM'02) received the B.Sc.(Eng.) and Ph.D degrees from Aberdeen University, Aberdeen, U.K., in 1977 and 1980, respectively. Academic appointments followed at Imperial College (1983-1990) and Cambridge University (1990-1997).

In 1997, he joined Invensys Brook Crompton (formerly Brook Crompton) as Head of Research responsible for motor technology. In 2000, he was appointed as Senior Lecturer at the University of Manchester Institute of Science and Technology, Manchester, U.K., and Reader in Electrical Machines in 2002. He became the Head of the Power Conversion Group in August 2002.

Dr. Smith is Executive Chairman of the Power Conversion and Applications Professional Network of the Institution of Electrical Engineers, U.K. 